\title{
Energy investment needs for fulfilling the Paris Agreement and achieving the Sustainable Development Goals
}

David L. McCollum ${ }^{1,2 *}$, Wenji Zhou ${ }^{1}$, Christoph Bertram ${ }^{3}$, Harmen-Sytze de Boer ${ }^{4}$, Valentina Bosetti $^{5,6}$, Sebastian Busch ${ }^{1}$, Jacques Després ${ }^{7}$, Laurent Drouet ${ }^{5}$, Johannes Emmerling ${ }^{5}$, Marianne Fay $^{8}$, Oliver Fricko ${ }^{1}$, Shinichiro Fujimori ${ }^{1,9}$, Matthew Gidden ${ }^{1}$, Mathijs Harmsen ${ }^{4,10}$, Daniel Huppmann ${ }^{1}$, Gokul Iyer ${ }^{11}$, Volker Krey ${ }^{1}$, Elmar Kriegler ${ }^{3}$, Claire Nicolas ${ }^{8}$, Shonali Pachauri ${ }^{1}$, Simon Parkinson ${ }^{1,12}$, Miguel Poblete-Cazenave ${ }^{1}$, Peter Rafaj ${ }^{1}$, Narasimha Rao ${ }^{1}$, Julie Rozenberg ${ }^{8}$, Andreas Schmitz ${ }^{7}$, Wolfgang Schoepp ${ }^{1}$, Detlef van Vuuren ${ }^{4,10}$, Keywan Riahi ${ }^{1,13}$

${ }^{1}$ International Institute for Applied Systems Analysis (IIASA), Schlossplatz 1, 2361 Laxenburg, Austria

${ }^{2}$ University of Tennessee, 1640 Cumberland Avenue, Knoxville, TN 37996, USA

${ }^{3}$ Potsdam Institute for Climate Impact Research (PIK), Telegraphenberg A 31, 14473 Potsdam, Germany.

${ }^{4}$ PBL Netherlands Environmental Assessment Agency, Bezuidenhoutseweg 30, 2594 AV, The Hague, The Netherlands

${ }^{5}$ EuroMediterranean Center on Climate Change (CMCC), C.so Magenta 6320123 Milano

${ }^{6}$ Bocconi University, via Sarfatti 25, 20136 Milan

7 Joint Research Centre (JRC), European Commission, Edificio Expo, C/ Inca Garcilaso 3, E-41092 Seville, Spain

8 The World Bank, 1818 H Street, NW, Washington, DC 20433, USA.

${ }^{9}$ National Institute for Environmental Studies (NIES), 16-2 Onogawa, Tsukuba-City, Ibaraki 305-8506, Japan

${ }^{10}$ Copernicus Institute for Sustainable Development, Utrecht University, Heidelberglaan 2, 3584 CS, Utrecht, The

Netherlands

11 Pacific Northwest National Laboratory (PNNL), 5825 University Research Court, Suite 3500, College Park, MD 20740, USA.

12 University of Victoria, PO Box 3055 STN CSC, Victoria, BC V8W 3P6, Canada

${ }^{13}$ Colorado School of Mines, 1500 Illinois Street, Golden, CO 80401, USA

${ }^{*}$ Corresponding author

\section{$\underline{\text { Abstract }}$}

Low-carbon investments are necessary for driving the energy system transformation called for by both the Paris Agreement and Sustainable Development Goals. Improving understanding of the scale and nature of these investments under diverging technology and policy futures is therefore of great importance to decision makers. Here, using six global modelling frameworks, we show that the pronounced reallocation of the investment portfolio required to transform the energy system will not be initiated by the current suite of countries' Nationally Determined Contributions. Charting a course toward 'well below $2{ }^{\circ} \mathrm{C}^{\prime}$ instead sees low-carbon investments overtaking fossil investments globally by around 2025 or before and growing significantly thereafter. Pursuing the $1.5^{\circ} \mathrm{C}$ target demands a marked up-scaling in low-carbon capital beyond that of a $2{ }^{\circ} \mathrm{C}$-consistent future. Actions consistent with an energy transformation would increase the costs of achieving energy access and food security goals but reduce those for achieving air quality goals. 
=ニニニニニニニニニニニニニニニニニニニニニニニニ

\section{MAIN TEXT}

ニニニニニニニニニニニニニニニニニニニニニニニニニ

Numerous pathways and narratives have been developed to shed light on how society could transform its energy systems in in line with the aspirational targets of the Paris Agreement and Sustainable Development Goals (SDGs) ${ }^{1-4}$. These studies make clear that ramping up renewables and boosting efficiency are necessary pre-conditions for limiting the rise in global temperatures to well below $2{ }^{\circ} \mathrm{C}$ during the $21^{\text {st }}$ century. Rarely, however, have these stories been told using the language of dollars, specifically energy investments, at least at the global level ${ }^{5-7}$, which is perhaps a bit surprising, given that investments are often recognized as the 'lifeblood' of the global energy system and that low-carbon investments act as the vehicle for the energy system transformation. Decision makers at all levels, including the G20 (Group of 20 countries), seem to be aware of this and are openly calling for such essential information ${ }^{8}$.

Scenario modelling tools are widely used to evaluate the costs, potentials, and consequences of different energy, climate, and human development futures over the medium-to-long term. Yet, analyses addressing global energy investment needs are fairly uncommon; even more so are multimodel exercises on the topic. The latter is important because each model has its own perspective on how the future could unfold, in light of varying assumptions for socio-economic development, technological change, and policy choices. Models also have different structures and solution algorithms.

Here we present key findings and insights from a multi-model analysis of the energy investments required for achieving increasingly stringent international policy goals over the coming decades. Scenarios are derived from six global energy-economy modelling frameworks, each of which depicts a uniquely evolving energy investment landscape in futures spanning a continuation of today's trends (considering countries' Nationally Determined Contributions (NDCs)) to those that are dramatically more transformative (consistent with achieving the aspirational $2{ }^{\circ} \mathrm{C}$ and $1.5^{\circ} \mathrm{C}$ targets espoused by the Paris Agreement ${ }^{\dagger}$ ). We focus our study in particular on the upscaling requirements and portfolio shifts inherent in these diverging futures, with an eye toward the most evident 'investment gaps'. We then compare these requirements with those for achieving other energy-related SDG targets ${ }^{10}$. In short, we find that a transformation of the global energy system need not require a major increase in investments in total. A pronounced reallocation of the investment portfolio is, however, inevitable. The NDCs will not provide the impetus for this structural shift. Instead, to chart a course toward 2 ${ }^{\circ} \mathrm{C}$ and $1.5^{\circ} \mathrm{C}$, annual investments in low-carbon energy (across the entire supply side, not just the power sector) will need to overtake fossil investments globally around 2025 or before. Going beyond a $2{ }^{\circ} \mathrm{C}$-consistent pathway and pushing closer to $1.5{ }^{\circ} \mathrm{C}$ is found to require a step-change in the amount of low-carbon capital invested per tonne of carbon dioxide $\left(\mathrm{CO}_{2}\right)$ avoided. We estimate that to achieve either the NDC, $2{ }^{\circ} \mathrm{C}$ or $1.5^{\circ} \mathrm{C}$ targets globally, there exists a low-carbon energy and energy efficiency investment 'gap' of approximately 130, 320, or 480 billion US\$/yr (to 2030; model averages), respectively, representing upwards of one-quarter of total energy investments otherwise 
foreseen in a baseline scenario; and for some major economies (e.g., China and India) up to onehalf. Moreover, total energy system investments can be up to an order of magnitude larger than the needs for making progress on several other SDG targets, such as energy access, food security, air pollution, education, and clean water and sanitation.

\section{Modelling tools employed}

The six global energy-economy models, or integrated assessment (IAM) frameworks, drawn upon in this study include AIM/CGE ${ }^{11,12}$, IMAGE ${ }^{13}$, MESSAGEix-GLOBIOM ${ }^{14,15}$, POLES ${ }^{16,17}$, REMINDMAgPIE ${ }^{18,19}$, and WITCH-GLOBIOM ${ }^{20,21}$; in addition, we employ the nationally-focused GCAMUSA $^{22,23}$ model for an analysis of power sector investments. (See Methods and Supplementary Methods for details on the modelling frameworks employed and policy scenarios run.) These models span a range from least-cost optimisation to computable general equilibrium models and from gametheoretic to recursive-dynamic simulation models. Such diversity is beneficial for shedding light on those model findings which are robust to diverging assumptions and on potential outliers deserving of further investigation. Of particular importance for the current study, the six models have broad coverage of different types of energy technologies across the entirety of the global energy system, including resource extraction, power generation, fuel conversion, pipelines/transmission, energy storage, and end-use/demand devices, and are therefore well-positioned to assess the evolving nature of the energy and climate mitigation investment portfolio over time. In order to highlight uncertainties in our analysis, throughout this paper we make use of both multi-model means and ranges $(\min / \max )$ when reporting our results. Given that our estimates are unable to capture all possible investment outcomes for a particular policy scenario, these means and ranges should be interpreted as being consistent with a 'middle-of-the-road' storyline for population, socio-economic development, and technology optimism, all under varying levels of climate policy stringency (see below). Key socio-economic and policy assumptions are harmonised in this study.

To put the multi-model results for energy investment needs into the context of investment needs for achieving or making progress on other sustainability objectives by 2030 , namely the United Nations' SDGs, we carry out additional calculations using external models and methodologies. We focus in particular on energy access ${ }^{24}$ (SDG7, Target 7.1), food security (2.1), air pollution ${ }^{25}$ (3.9), quality education $^{26}(4.1)$, and clean water and sanitation ${ }^{27,28}(6.1,6.2,6.3,6.4)$. The advantage of using investments to compare across sustainability dimensions is that their disparate objectives are otherwise difficult, if not impossible, to relate.

\section{Scenarios depicted}

Four scenarios are explored in this paper (see Methods). 'Current Policies' ('CPol') serves as each model's reference case (or baseline). The scenario takes into account those energy- and climaterelated policies that were already "on the books" of countries as of 2015; in other words, it reflects the early bridges to the low-carbon economy that policy makers have already implemented in various parts of the world. In addition to the reference case, the modelling teams each ran three scenarios 
where policies for low-carbon energy, energy efficiency, and climate change mitigation are tightened: 'Nationally Determined Contributions' ('NDC'), 'Well Below 2 Degrees' ('2C'), and 'Toward 1.5 Degrees' ('1.5C’). Population and socio-economic development assumptions across all scenarios are in line with the 'middle-of-the-road' storyline of the Shared Socioeconomic Pathways (SSP2) ${ }^{14,29}$.

\section{Base-year energy investments and their uncertainties}

Total investments in the global energy system were approximately 1800 billion US \$2015/yr in 2015 (excluding fuel and operations and maintenance costs), according to the International Energy Agency (IEA) ${ }^{30,31}$. This amounted to over $2 \%$ of global gross domestic product (GDP) and 10\% of gross capital formation in that year. The vast majority of these investments ( 1600 billion US\$/yr) were made to add or replace equipment on the supply side of the energy system, while a further 220 billion US $\$ / y r$ was invested in energy efficiency across the end-use sectors (buildings, transport and industry). A breakdown of 2015 investments among the supply-side sectors is illustrated in Figure 1. (Supplementary Note 1 provides additional details, including an elaboration on the uncertainties surrounding historical estimates of energy investments.) The IEA values shown here are calculated based on similar methodologies as this study's six models; we therefore use estimates from the models to cross-check the IEA (see uncertainty bars in Figure 1). The latter appears to be well within the bounds of uncertainty for total investments, yet for several of the sub-categories there are notable differences. For instance, the IEA generally estimates higher fossil fuel extraction and conversion investments than the models. This is due to a mix of factors, including, among others, uncertainties surrounding when exactly investments responsible for new capacity additions are made (important for oil refinery 'creep' for instance), the varied treatment of oil and natural gas exploration expenditures across models, and the fact that 2015 is actually a 'constrained projection year' in some frameworks. 


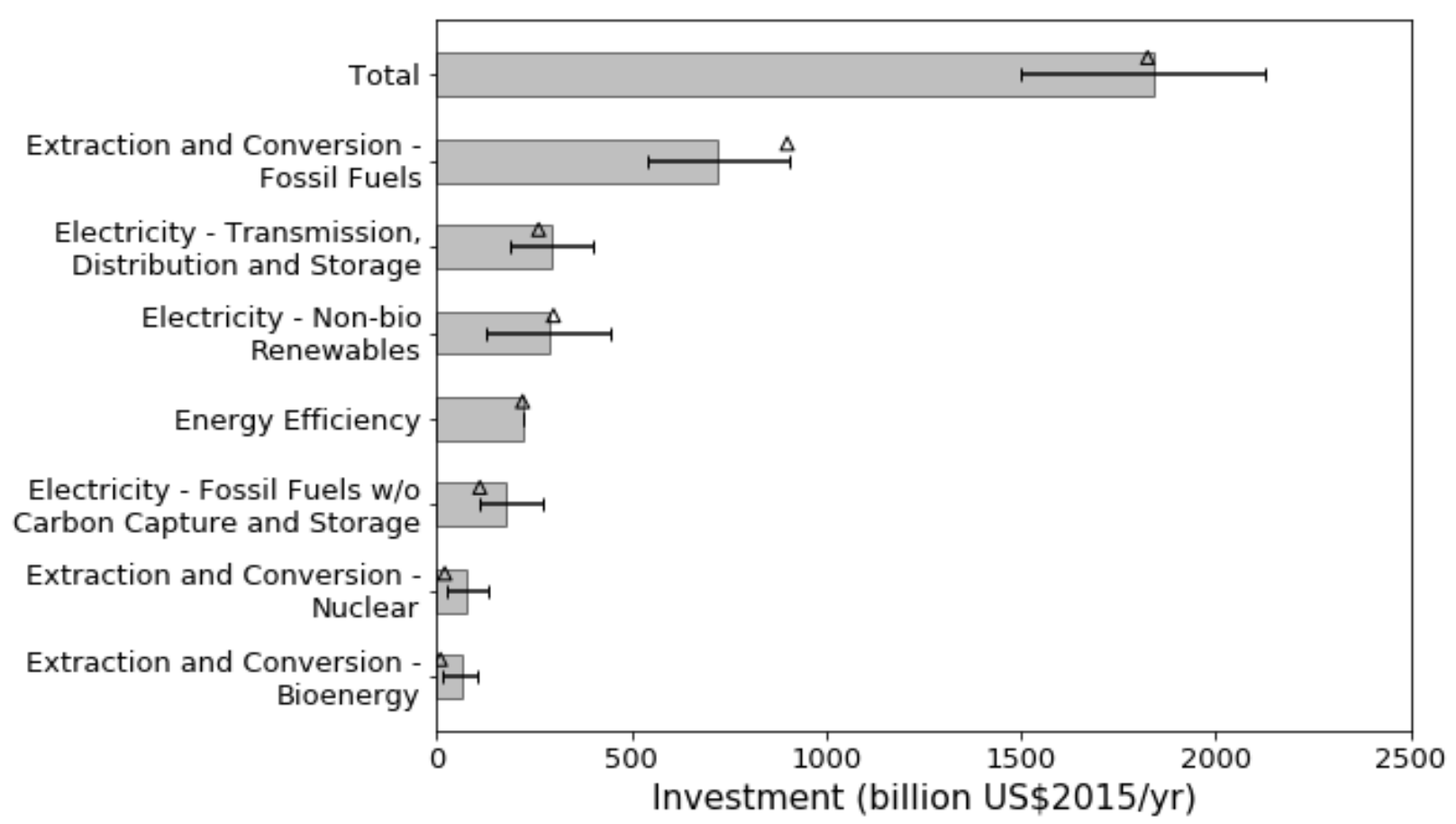

Figure 1. Global energy investments by category in 2015. Triangles represent IEA estimates and are taken from ref 30. Bar values represent multi-model means; bar whiskers give the min-max ranges across the models. Base-year 2015 estimates for energy efficiency investments are only available from IEA ${ }^{30}$, not from the models, given differing calculation methodologies. IEA values for efficiency investments are thus assumed for all the models in 2015.

Future energy investment needs across the scenarios

A growing population with increasing demand for energy implies larger overall levels of global energy investment going forward. And in fact this is what is exhibited by nearly all of the models' scenarios: total average annual investments over the 2016-2050 period (undiscounted) are higher than in 2015 (Figure 2). Investment estimates by IEA and the International Renewable Energy Agency (IRENA) for scenarios analogous to this study's 'NDC' and '2C' cases exhibit the same dynamics ${ }^{6}$. Model differences can be explained by endogenously determined technology choices, and varying representations for how unit-level capital costs evolve over time. (For underlying yearly, regional, and sectoral investment data underlying the figures and tables in this paper, please see Supplementary Data 1.) Note that in this paper we focus on the investment period to 2050 , even though each of the IAMs runs to 2100 in its scenarios. Moreover, given the nature of these models, we expressly address the question of 'where are the investment needs', not 'who pays for them'.

The impact of future energy and climate policies on total energy investments depends on the nature and extent of those policies. Meeting countries most recent pledges ('NDC' scenario) would likely only necessitate a marginal increase in total future investments, relative to a continuation of current trends ('CPol'). In contrast, more aggressive policies promoting an energy system transformation ('2C' and ' $1.5 \mathrm{C}$ ' pathways) would, according to most models, require a marked increase (Figure 2). IEA's and IRENA's estimates for the total investment needs in a ' $2 \mathrm{C}$ '-consistent scenario are found 
to be toward the lower end of the range of the models. One of the principal reasons why supply-side investments do not increase more than one might expect in these pathways, or why some models project them to decline, is because of the rapid acceleration in demand-side energy efficiency and conservation investments foreseen, relative to the 'CPol' and 'NDC' cases. (There is no generally accepted methodology for calculating such investments; see Methods for a description of ours.) As a share of global GDP, the total energy investments projected by the models do not rise significantly from today in any of the scenarios, hovering just over $2 \%$ (model range: $1.5-2.6 \%$ ) in 'CPol' and 'NDC' and growing to $2.5 \%(1.6-3.4 \%)$ and $2.8 \%(1.8-3.9 \%)$ in the ' $2 \mathrm{C}$ ' and ' $1.5 \mathrm{C}$ ' pathways, respectively. Regional results can be quite different though.

Moreover, we note that the models exhibiting the largest increase in supply-side investments in the '2C' and '1.5C' pathways (AIM/CGE and REMIND-MAgPIE) are also the ones with the most rapid up-scaling of renewable electricity capacity, principally solar photo-voltaic and wind. This, by extension, has implications for increased electricity transmission and distribution (T\&D) and storage investments. In Supplementary Notes 2, 6 and 7 and Supplementary Figures 1 and 2, we show and explain some of these trends, including relating the models' assumed capital costs for different electricity generation technologies to the deployment levels and investment magnitudes that are seen.

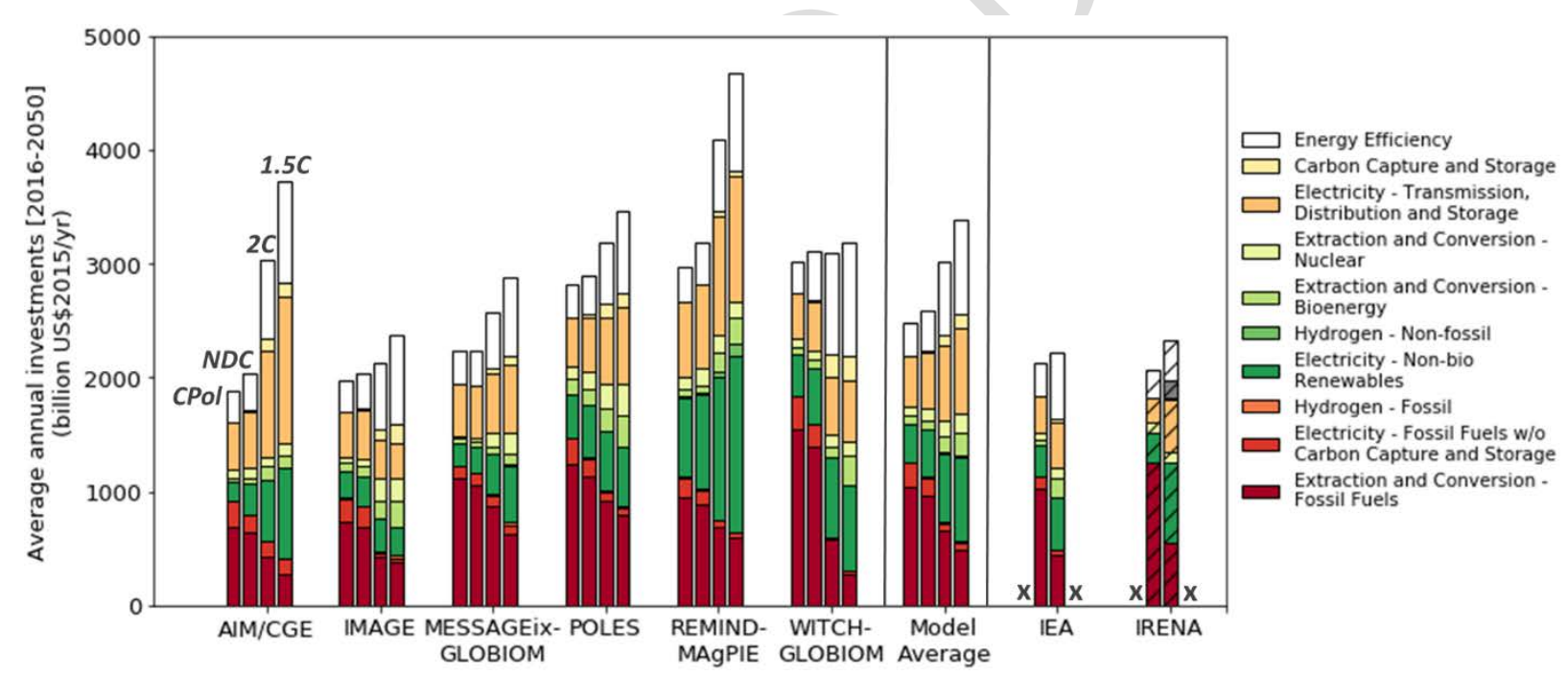

Figure 2. Projected global average annual energy investments by category from 2016 to 2050 according to different models. Values are calculated by cumulating the models' undiscounted investment estimates and averaging them over the full 2016-2050 period. Source of IEA and IRENA supply-side investment numbers is ref ${ }^{6}$. Lack of complete data in the IRENA case does not allow for a full breakdown of results into the investment categories used here (hence the cross-hatching). Analogous versions of the 'CPol' and ' $1.5 \mathrm{C}$ ' scenarios are not available from IEA and IRENA (hence the ' $x$ ' markers). Energy efficiency investments for IEA and IRENA are calculated by the authors using the same methodology as for the models, except that the IEA and IRENA baselines are taken as their respective 'NDC' analogous scenarios; this leads to a slight underestimate of the IEA and IRENA efficiency investments. 
Table 1. Projected global and regional average annual energy investments by category from 2016 to 2050 . Multimodel means are provided along with $\mathrm{min} / \mathrm{max}$ ranges across models in parentheses. Values are calculated by cumulating the models' undiscounted investment estimates and averaging them over the full 2016-2050 period. Energy efficiency investments listed for the regions (other than 'World') are known to be underestimates, since they include only the 'supply-side offset' component of the calculation, whereas the global energy efficiency investments include both this and the 'base-year efficiency' component. The latter is available as an estimate by IEA only at the global level (see Methods for details), hence the varying treatment.

\begin{tabular}{|c|c|c|c|c|c|c|c|c|c|c|c|c|}
\hline & & $\begin{array}{l}\text { Extraction and } \\
\text { Conversion - } \\
\text { Fossil Fuels }\end{array}$ & $\begin{array}{c}\text { Electricity - } \\
\text { Fossil Fuels } \\
\text { w/o Carbon } \\
\text { Capture and } \\
\text { Storage }\end{array}$ & $\begin{array}{l}\text { Hydrogen - } \\
\text { Fossil }\end{array}$ & $\begin{array}{c}\text { Electricity - } \\
\text { Non-biomass } \\
\text { Renewables }\end{array}$ & $\begin{array}{l}\text { Hydrogen - } \\
\text { Non-fossil }\end{array}$ & $\begin{array}{c}\text { Extraction and } \\
\text { Conversion - } \\
\text { Bioenergy }\end{array}$ & $\begin{array}{l}\text { Extraction and } \\
\text { Conversion - } \\
\text { Nuclear }\end{array}$ & $\begin{array}{c}\text { Electricity - } \\
\text { Transmission \& } \\
\text { Distribution } \\
\text { and Storage }\end{array}$ & $\begin{array}{l}\text { Carbon Capture } \\
\text { and Storage }\end{array}$ & $\begin{array}{l}\text { Demand-Side } \\
\text { Energy } \\
\text { Efficiency }\end{array}$ & $\begin{array}{c}\text { Total } \\
\text { (Supply + } \\
\text { Demand) }\end{array}$ \\
\hline & & \multicolumn{11}{|c|}{ CPol } \\
\hline & WORLD & 1041 (682 to 1544$)$ & 206 (113 to 300$)$ & $6(0$ to 13$)$ & 343 (183 to 698$)$ & $2(0$ to 11$)$ & $64(26$ to 129$)$ & 75 (16 to 113$)$ & 458 (393 to 664$)$ & $0(0$ to 3$)$ & 285 (274 to 303$)$ & 2481 (1885 to 3014) \\
\hline \multirow{5}{*}{ 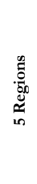 } & ASIA & 230 (101 to 410$)$ & 94 (46 to 132$)$ & $2(0$ to $\theta)$ & 145 (74 to 329$)$ & $1(0$ to 5$)$ & 19 (4 to 41$)$ & $34(5$ to 82$)$ & 188 (135 to 329$)$ & $0(0$ to 0$)$ & $0(0$ to 0$)$ & 713 (383 to 1276$)$ \\
\hline & LAM & 121 (51 to 215 ) & $9(1$ to 17$)$ & 0 (0 to 2$)$ & 32 (12 to 69$)$ & 0 (0 to 1$)$ & $8(3$ to 17$)$ & $2(0$ to 5$)$ & 32 (20 to 51$)$ & $0(0$ to 0$)$ & $0(0$ to 0$)$ & 204 (105 to 284 ) \\
\hline & MAF & 320 (119 to 459$)$ & $28(14$ to 51$)$ & 0 (0 to 1) & $27(12$ to 71$)$ & 0 (0 to 2) & 12 (1 to 28$)$ & $4(0$ to 11$)$ & 54 (28 to 92$)$ & $0(0$ to 0$)$ & $0(0$ to 0$)$ & 445 (323 to 588$)$ \\
\hline & OECD90 & 239 (68 to 388$)$ & $60(34$ to 126$)$ & $4(0$ to 11$)$ & 126 (53 to 219$)$ & $1(0$ to 3$)$ & 26 (9 to 56) & 24 (1 to 45$)$ & 157 (115 to 180$)$ & $0(0$ to 3$)$ & $0(0$ to 0$)$ & 636 (447 to 823$)$ \\
\hline & REF & $113(20$ to 190$)$ & 15 (5 to 37$)$ & $0(0$ to 0$)$ & 8 (4 to 12$)$ & $0(0$ to 0$)$ & 1 (0 to 3$)$ & $6(0$ to 22$)$ & 27 (13 to 40$)$ & $0(0$ to 0$)$ & $0(0$ to 0$)$ & 171 (55 to 292$)$ \\
\hline \multirow{4}{*}{ 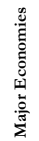 } & China & 138 (70 to 223 ) & 50 (16 to 80$)$ & $1(0$ to 3$)$ & $86(37$ to 173$)$ & $0(0$ to 2$)$ & 4 (1 to 13$)$ & $21(4$ to 54$)$ & 101 (70 to 169$)$ & $0(0$ to 0$)$ & $0(0$ to 0$)$ & $402(251$ to 670$)$ \\
\hline & India & 37 (17 to 86 ) & 26 (8 to 34$)$ & $0(0$ to 2$)$ & $33(8$ to 83$)$ & $0(0$ to 1$)$ & $4(1$ to 10$)$ & $6(0$ to 11$)$ & $46(15$ to 83$)$ & $0(0$ to 0$)$ & $0(0$ to 0$)$ & 153 (51 to 299$)$ \\
\hline & Europe & 66 (26 to 138$)$ & $12(7$ to 19$)$ & $2(0$ to 5$)$ & 60 (26 to 98$)$ & $0(0$ to 1$)$ & $14(2$ to 25$)$ & $8(0$ to 14$)$ & $59(42$ to 73$)$ & 0 (0 to 2$)$ & $0(0$ to 0$)$ & 221 (131 to 301$)$ \\
\hline & USA & $120(45$ to 165$)$ & 29 (16 to 52$)$ & $2(0$ to 4$)$ & 40 (20 to 71$)$ & $0(0$ to 1$)$ & $10(1$ to 18$)$ & $9(0$ to 21$)$ & 63 (46 to 85$)$ & $0(0$ to 0$)$ & $0(0$ to 0$)$ & $273(217$ to 318$)$ \\
\hline
\end{tabular}

\begin{tabular}{|c|c|c|c|c|c|c|c|c|c|c|c|c|}
\hline & & & & & & & $N D C$ & & & & & \\
\hline & WORLD & 965 (640 to 1397$)$ & $153(107$ to 199$)$ & $6(0$ to 15$)$ & 424 (221 to 833$)$ & $2(0$ to 11$)$ & $72(42$ to 136$)$ & $99(30$ to 161$)$ & 501 (423 to 734 ) & 11 (3 to 30$)$ & $352(313$ to 440$)$ & 2586 (2037 to 3183$)$ \\
\hline \multirow{5}{*}{ 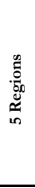 } & ASIA & $214(132$ to 379$)$ & $67(38$ to 100$)$ & $2(0$ to 7$)$ & 181 (86 to 397 ) & $1(0$ to 5$)$ & 21 (5 to 45$)$ & 48 (8 to 106$)$ & 202 (142 to 359$)$ & 4 (0 to 12$)$ & $26(-4$ to 71$)$ & 766 (426 to 1378 ) \\
\hline & LAM & 109 (42 to 193 ) & $6(0$ to 13$)$ & 1 (0 to 2$)$ & 35 (14 to 77 ) & 0 (0 to 1$)$ & 10 (4 to 18 ) & $3(0$ to 8$)$ & 34 (21 to 57$)$ & $1(0$ to 2$)$ & 8 (1 to 21) & 207 (103 to 281) \\
\hline & MAF & 305 (131 to 429$)$ & $26(14$ to 46$)$ & $0(0$ to 1$)$ & $30(12$ to 81$)$ & $0(0$ to 2$)$ & $13(2$ to 29$)$ & 4 (0 to 12$)$ & 56 (30 to 98$)$ & $0(0$ to 1$)$ & $3(-3$ to 6$)$ & 438 (339 to 568$)$ \\
\hline & OECD 90 & 212 (31 to 339$)$ & $40(24$ to 69$)$ & $3(0$ to 9$)$ & 162 (66 to 264$)$ & 1 (0 to 3$)$ & 29 (10 to 59$)$ & $32(5$ to 60$)$ & 181 (124 to 252$)$ & 5 (1 to 17$)$ & 31 (13 to 66$)$ & 695 (466 to 894 ) \\
\hline & REF & $110(23$ to 190$)$ & $14(5$ to 38$)$ & $0(0$ to 0$)$ & $10(4$ to 15$)$ & $0\langle 0$ to 0$)$ & $2(0$ to 3$)$ & $6(0$ to 20$)$ & $28(13$ to 44$)$ & $0(0$ to 1$)$ & $0(-5$ to 4$)$ & $169(60$ to 287$)$ \\
\hline \multirow{4}{*}{ 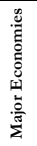 } & China & 127 (98 to 212$)$ & 31 (17 to 50$)$ & 1 (0 to 3$)$ & 111 (43 to 199 ) & 0 (0 to 2$)$ & 5 (1 to 17$)$ & $28(4$ to 68$)$ & 109 (82 to 181$)$ & $3(0$ to 10$)$ & $18(-2$ to 69$)$ & 434 (266 to 705 ) \\
\hline & India & 38 (20 to 93 ) & 24 (7 to 35$)$ & $0(0$ to 2$)$ & 38 (9 to 99$)$ & $0(0$ to 1$)$ & $5(1$ to 10$)$ & $6(0$ to 11$)$ & 48 (17 to 89 ) & $0(0$ to 0$)$ & $0(-1$ to 4$)$ & 160 (58 to 328$)$ \\
\hline & Europe & 60 (24 to 123$)$ & 9 (5 to 15$)$ & $2(0$ to 4$)$ & 69 (27 to 107$)$ & 0 (0 to 1$)$ & 14 (3 to 25$)$ & $10(0$ to 20$)$ & 63 (46 to 79$)$ & 2 (0 to 8$)$ & $6(3$ to 11$)$ & 236 (138 to 327$)$ \\
\hline & USA & 105 (21 to 143$)$ & $17(6$ to 27$)$ & $2(0$ to 4$)$ & 59 (32 to 100$)$ & 0 (0 to 1$)$ & $11(2$ to 19$)$ & $14(1$ to 29$)$ & $76(53$ to 104$)$ & $2(0$ to 6$)$ & $16(7$ to 36$)$ & 301 (238 to 346$)$ \\
\hline
\end{tabular}

\begin{tabular}{|c|c|c|c|c|c|c|c|c|c|c|c|c|}
\hline & & & & & & & $2 C$ & & & & & \\
\hline & WORLD & 649 (419 to 917$)$ & 70 (26 to 128$)$ & $8(0$ to 17$)$ & $609(295$ to 1255$)$ & $9(0$ to 42$)$ & 132 (67 to 200$)$ & $145(84$ to 220$)$ & 654 (338 to 1048$)$ & 102 (34 to 204) & 636 (483 to 893 ) & \begin{tabular}{|l|l|}
$3017(2130$ to 4094 \\
\end{tabular} \\
\hline \multirow{5}{*}{ 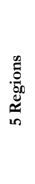 } & ASIA & 137 (40 to 272$)$ & $26(6$ to 44$)$ & $3(0$ to 8$)$ & $278(97$ to 626$)$ & $4(0$ to 17$)$ & 50 (17 to 103 ) & 81 (21 to 141$)$ & 272 (125 to 523$)$ & 35 (8 to 76$)$ & 157 (79 to 263 ) & 1043 (680 to 1829$)$ \\
\hline & LAM & 70 (22 to 133 ) & 2 (0 to 4$)$ & $0(0$ to 1$)$ & $46(30$ to 88$)$ & 1 (0 to 6$)$ & 22 (6 to 44$)$ & $4(0$ to 11$)$ & 44 (31 to 76$)$ & $5(3$ to 10$)$ & 29 (20 to 44$)$ & 223 (161 to 307$)$ \\
\hline & MAF & 191 (22 to 305$)$ & $9(3$ to 13$)$ & $1(0$ to 2$)$ & 59 (27 to 156$)$ & 1 (0 to 7$)$ & 44 (8 to 158$)$ & $8(0$ to 20$)$ & 75 (36 to 152$)$ & 16 (12 to 21$)$ & 75 (48 to 91 ) & 479 (291 to 571 ) \\
\hline & OECD 90 & 150 (29 to 243$)$ & 29 (6 to 77$)$ & $4(0$ to 8$)$ & $200(87$ to 354$)$ & $2(0$ to 11$)$ & 48 (27 to 78 ) & $34(18$ to 61$)$ & 228 (136 to 355$)$ & 38 (10 to 88 ) & $94(50$ to 219$)$ & 827 (562 to 1004 ) \\
\hline & REF & 71 ( 8 to 158$)$ & 4 (2 to 13$)$ & 1 (0 to 2$)$ & 21 (5 to 41$)$ & $0(0$ to 0$)$ & 4 (1 to 7$)$ & 9 (2 to 30) & 34 (10 to 80$)$ & $10(1$ to 21$)$ & 35 (13 to 74$)$ & $188(78$ to 250$)$ \\
\hline \multirow{4}{*}{ 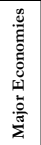 } & China & $82(25$ to 149$)$ & 14 (2 to 26) & $1(0$ to 4$)$ & $166(45$ to 306$)$ & $3(0$ to 11$)$ & 9 (3 to 20$)$ & $46(5$ to 95$)$ & 156 (45 to 259$)$ & 18 (3 to 57$)$ & 90 (44 to 170$)$ & 583 (347 to 922 ) \\
\hline & India & $22(9$ to 57$)$ & 5 (1 to 11$)$ & $1(0$ to 3$)$ & 67 (22 to 174$)$ & 1 (0 to 3$)$ & $13(3$ to 27$)$ & $19(4$ to 50$)$ & $63(40$ to 138$)$ & 9 (3 to 21) & $35(16$ to 71$)$ & 235 (120 to 453$)$ \\
\hline & Europe & $43(18$ to 79$)$ & $6(2$ to 13$)$ & $1(0$ to 3$)$ & 75 (38 to 129$)$ & 1 (0 to 4$)$ & $18(6$ to 30$)$ & 9 (5 to 12$)$ & 71 (46 to 98$)$ & 11 (1 to 23) & $27(9$ to 67$)$ & 263 (164 to 359$)$ \\
\hline & USA & 81 (21 to 130$)$ & $12(1$ to 25$)$ & 2 (0 to 4 ) & 79 (41 to 142$)$ & 1 (0 to 6$)$ & $23(7$ to 40$)$ & 15 (2 to 29$)$ & 100 (68 to 156$)$ & 16 (4 to 40$)$ & 40 (16 to 96$)$ & 369 (286 to 415$)$ \\
\hline
\end{tabular}

\begin{tabular}{|c|c|c|c|c|c|c|c|c|c|c|c|c|}
\hline & & & & & & & $1.5 C$ & & & & & \\
\hline & WORLD & 490 (275 to 788 ) & 62 (22 to 130$)$ & $13(0$ to 35$)$ & 730 (248 to 1550$)$ & $19(0$ to 99$)$ & 200 (94 to 284) & 171 (110 to 265$)$ & 750 (298 to 1285$)$ & 124 (41 to 205 ) & 822 (691 to 992 ) & 3381 (2366 to 4677 ) \\
\hline \multirow{5}{*}{ 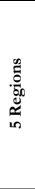 } & ASIA & $110(26$ to 236$)$ & $21(4$ to 35$)$ & 4 (0 to 10$)$ & $327(72$ to 768$)$ & $8(0$ to 39$)$ & 101 (24 to 323) & $91(29$ to 164$)$ & 312 (102 to 548 ) & $41(9$ to 68$)$ & 241 (174 to 318$)$ & 125 (837 to 2084) \\
\hline & LAM & 51 (10 to 123$)$ & $2(0$ to 3$)$ & 1 (0 to 2) & 51 (24 to 99) & $2(0$ to 13$)$ & $25(17$ to 49$)$ & 5 (1 to 17$)$ & $48(25$ to 77$)$ & 9 (3 to 12) & $36(17$ to 53$)$ & 230 (162 to 350$)$ \\
\hline & MAF & $129(19$ to 211$)$ & 8 (2 to 12$)$ & $1(0$ to 3$)$ & 79 (20 to 214$)$ & $3(0$ to 15$)$ & 99 (11 to 453$)$ & 10 (0 to 25$)$ & 88 (30 to 164$)$ & 16 (4 to 23$)$ & $96(73$ to 138$)$ & 529 (278 to 750$)$ \\
\hline & OECD 90 & 119 (19 to 228 ) & 28 (6 to 87$)$ & 6 (0 to 20) & 238 (128 to 433 ) & 6 (0 to 31$)$ & $68(34$ to 107$)$ & $44(23$ to 67$)$ & 262 (131 to 477$)$ & $49(15$ to 96$)$ & 163 (100 to 308$)$ & 985 (697 to 1196 ) \\
\hline & REF & 53 (7 to 108$)$ & $3(1$ to 10$)$ & $1(0$ to 4$)$ & $30(5$ to 60$)$ & $0(0$ to 1$)$ & $10(2$ to 32$)$ & $10(3$ to 30$)$ & 39 (9 to 100$)$ & 9 (1 to 19$)$ & $50(19$ to 82$)$ & $206(89$ to 289$)$ \\
\hline \multirow{4}{*}{ 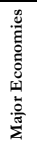 } & China & 63 (18 to 127$)$ & 12 (2 to 23$)$ & $2(0$ to 5$)$ & $194(35$ to 370$)$ & 4 (0 to 21) & $16(7$ to 23$)$ & 52 (5 to 122$)$ & $182(36$ to 325$)$ & $19(4$ to 45$)$ & 133 (105 to 196$)$ & 677 (364 to 1034$)$ \\
\hline & India & $19(5$ to 49$)$ & $4(1$ to 7$)$ & 1 (0 to 3$)$ & 79 (17 to 216$)$ & $2(0$ to 6$)$ & $21(3$ to 49$)$ & $20(5$ to 49$)$ & 72 (34 to 141$)$ & 11 (3 to 23) & $60(33$ to 109$)$ & 288 (190 to 526$)$ \\
\hline & Europe & $33(19$ to 71 ) & 6 (2 to 14$)$ & $2(0$ to 5$)$ & 86 (46 to 152$)$ & 3 (0 to 11$)$ & $24(12$ to 37$)$ & $10(8$ to 13$)$ & $76(45$ to 103$)$ & 14 (2 to 24$)$ & 48 (20 to 102$)$ & 302 (196 to 407$)$ \\
\hline & USA & 66 (13 to 124$)$ & 11 (2 to 25$)$ & $4(0$ to 13$)$ & 96 (61 to 180$)$ & $2(0$ to 13$)$ & 28 (14 to 69$)$ & $20(3$ to 30$)$ & 112 (66 to 198$)$ & $22(9$ to 47$)$ & $70(43$ to 125$)$ & 431 (338 to 507$)$ \\
\hline
\end{tabular}




\section{A shifting energy investment landscape}

Of perhaps greater significance to investors than total capital flows is how the energy investment portfolio might be expected to evolve over time under varying assumptions for future energy and climate policies. That portfolio continues to look very similar to today in the 'CPol' baseline, and to a large extent also in the 'NDC' case (Figure 2 and Table 1). In contrast, the transformational '2C' and ' $1.5 \mathrm{C}$ ' pathways exhibit a shift from fossil (especially coal) to low-carbon and efficiency investments that is much more pronounced (Figure 3; see Supplementary Note 3 for further discussion). Additionally, several models provide evidence of significantly increased investment requirements for electricity $\mathrm{T} \& \mathrm{D}$ and storage, driven by greater demands for delivering electricity to the end-use sectors (buildings, industry, and transport) and by the intermittency of variable renewable electricity sources.

(a)

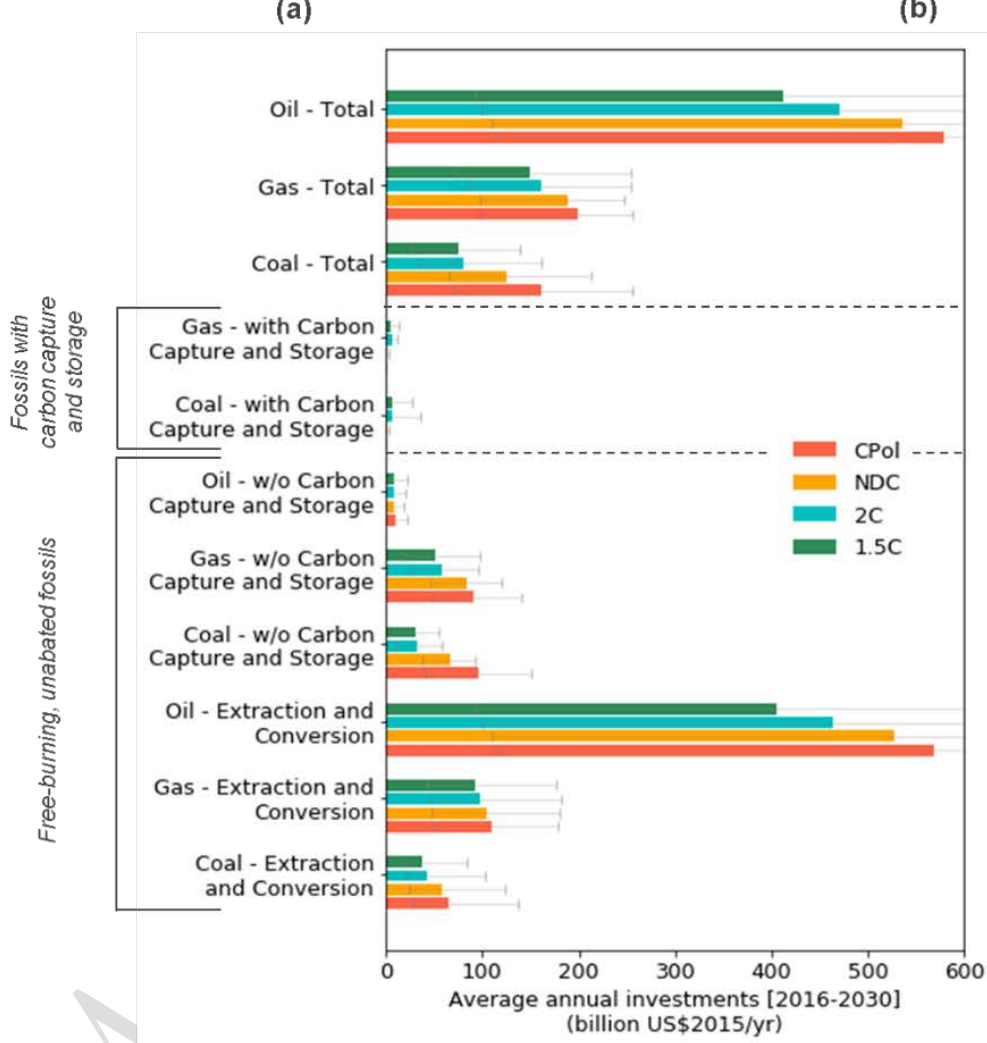

(b)

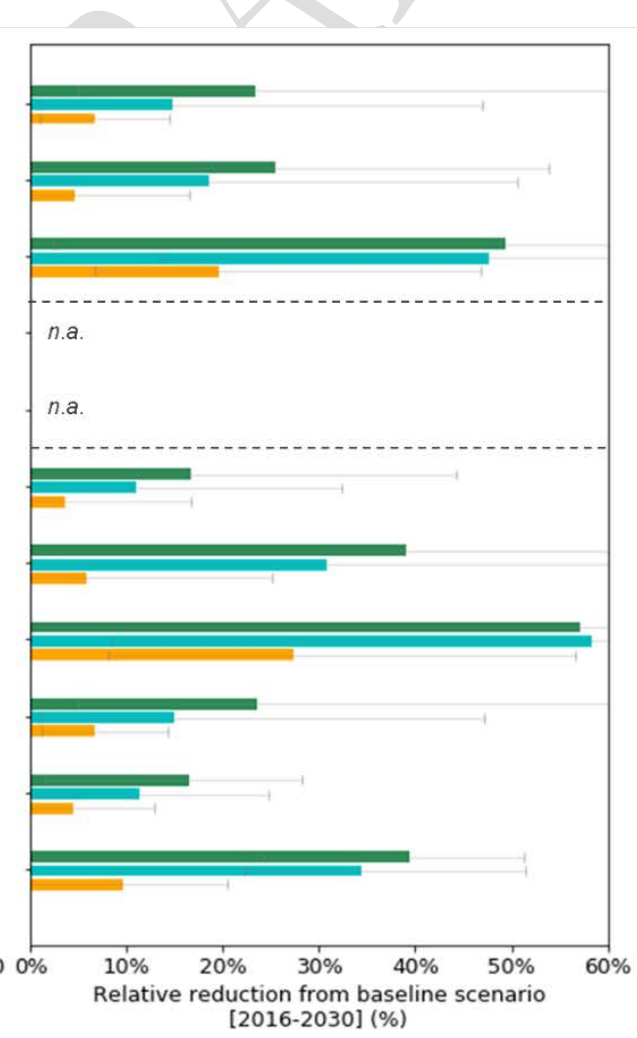

Figure 3. Projected global average annual fossil fuel supply investments and changes by category from 2016 to 2030. (a) average annual investments. (b) relative reduction in investments from the 'CPol' baseline scenario. Values are calculated by cumulating the models' undiscounted investment estimates and averaging them over the full 2016-2050 period. Bar values represent multi-model means; bar whiskers give the min-max ranges across the models. Relative changes cannot be calculated for natural gas and coal electricity generation with carbon capture and storage because the values in the 'CPol' baseline are zero (thus 'n.a.' = not applicable). Dashed lines are used to visually separate categories.

Declines in unabated (i.e., not equipped with carbon capture and storage, CCS) coal, gas, and oil investments imply increases in renewables, nuclear, and demand-side energy efficiency (and to a lesser extent fossils equipped with CCS; see Figure 3), especially in the more transformative '2C' and '1.5C' pathways. The models provide evidence of an inverse relationship between average annual 
low-carbon energy investments over the near and medium terms (to 2030 and 2050, respectively) and cumulative carbon emissions over the long term (to 2100; see Figure 4): in other words, as investments in low-carbon energy and energy efficiency are progressively scaled up, cumulative $\mathrm{CO}_{2}$ emissions can be expected to consistently decline. While absolute investment numbers may vary to some extent, the inverse investment-emissions relationship is common across nearly all models for the two different time periods, even if the slopes vary. The IMAGE model exhibits particularly unique behaviour over the near term (Figure 4, panel 'a'), with the 'NDC' scenario showing greater low-carbon energy investment requirements than the ' $2 \mathrm{C}$ ' pathway. This results from explicitly modelled renewable energy capacity targets that derive from the NDC pledges but are not modelled in the other scenarios, and lower demands for electricity generation, and thus capacity additions, over the 2020-2030 period in the more stringent '2C' (and ' $1.5 \mathrm{C}$ '), owing to the substantial carbon price. While the underlying dynamics of other models may be similar, the inter-temporal effects in IMAGE are far stronger.

An inflection point for the investment-emissions relationship appears to be somewhere around 1000 $\mathrm{GtCO}_{2}$, which is the level targeted by the models in the '2C' scenario. After that cumulative emissions threshold has been reached, nearly all of the models show a kink in the curves, such that an additional reduction of a relatively small amount of $\mathrm{CO}_{2}$ requires a disproportionate increase in investments. Put differently, the incremental low-carbon energy and efficiency investments needed to go beyond the achievement of the $2{ }^{\circ} \mathrm{C}$ target and push closer toward $1.5{ }^{\circ} \mathrm{C}$ could require a stepchange in terms of capital invested per tonne of $\mathrm{CO}_{2}$ avoided, relative to the energy system transformation efforts that have occurred up to that point (i.e., from 'CPol' to 'NDC' and then on to ' $2 \mathrm{C}$ '). Driving this step-change is greater reliance on, and a far accelerated deployment of, more capital-intensive renewable energy, nuclear power, and electricity T\&D and storage technologies. At the same time, less capital-intensive fossil energy extraction and conversion technologies see an even faster phase-out in the ' $1.5 \mathrm{C}$ ' case than in ' $2 \mathrm{C}$ '.

(a)

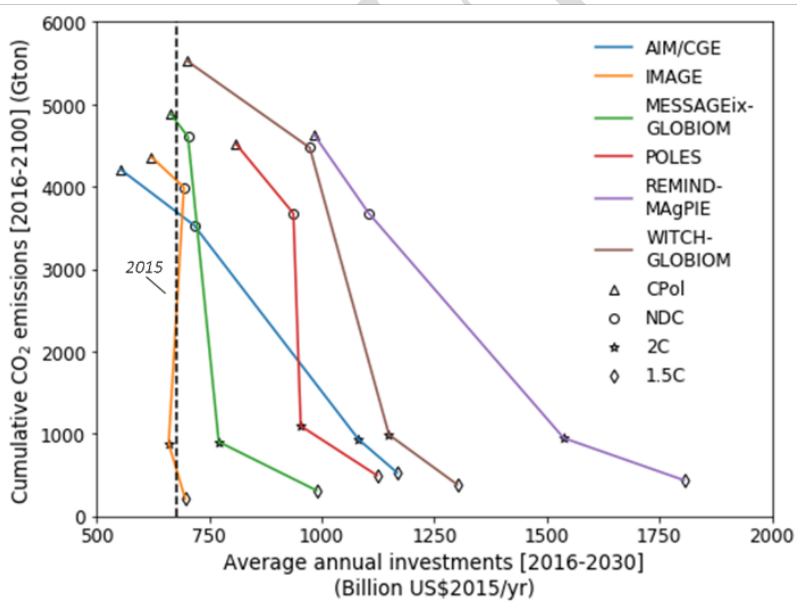

(b)

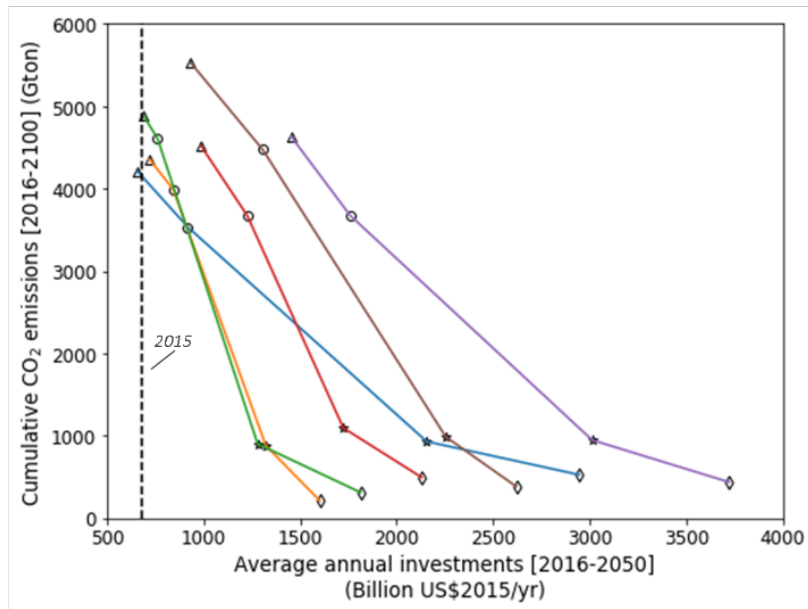

Figure 4. Projected global average annual low-carbon energy investments and cumulative carbon emissions. (a) 2016-2030. (b) 2016-2050. Values are calculated by cumulating the models' undiscounted investment estimates and averaging them over the full 2016-2050 period. Investment estimates include two aspects: first, supply-side investments in renewable electricity and hydrogen production, bioenergy extraction and conversion, uranium mining and nuclear power, fossil energy equipped with CCS, and the portion of electricity T\&D and storage investments that can be attributed to low-carbon electricity generation, and second, demand-side investments in energy efficiency and 
conservation. Comparable value for 2015 denoted by vertical line ( 680 billion US $\$$ /yr). Cumulative carbon emissions include fossil fuel and industrial (FF\&I) $\mathrm{CO}_{2}$ between 2016 and 2100.

\section{Low-carbon energy investment shares}

Professionals engaged in the business of 'green financing' (i.e., those responsible for mobilising capital to launch low-carbon energy and efficiency projects) should be aware of the stepped-up investment effort required to lay the groundwork for a future consistent with $2{ }^{\circ} \mathrm{C}$, and even more so $1.5^{\circ} \mathrm{C}$. The NDC pledges made by countries over the past two years are certainly a move in the right direction, but they are clearly insufficient for incentivising the kind of deeper, structural changes in the energy investment portfolio required for reaching the lower temperature targets of the Paris Agreement ${ }^{32}$ (see previous sections). By our calculations, full implementation of the NDCs by countries throughout the world would require that low-carbon supply-side investment shares grow over the next decades to levels somewhat higher than today, yet remaining below $50 \%$ up to mid-century (Figure 5; multi-model means shown; individual model results vary as exhibited in Supplementary Figure 3). In other words, total low-carbon investments would continue to remain smaller than fossil investments for the foreseeable future. The ' $2 \mathrm{C}$ ' and ' $1.5 \mathrm{C}$ ' pathways offer a marked departure from these trends, with low-carbon supply-side investments overtaking fossil investments already by around 2025 or before. Then, some years later low-carbon supply-side investments would need to reach and/or surpass the $80 \%$ threshold, a mark that is projected to occur close to mid-century in the '2C' pathway and much sooner $(\sim 2035)$ in the '1.5C' case. Unabated fossil investments (without CCS) never drop fully to $0 \%$ during the first half of the century, even in the ' $1.5 \mathrm{C}$ ' pathway - a finding of particular note considering that many scenarios point to the need for fossil fuel and industrial (FF\&I) $\mathrm{CO}_{2}$ emissions to cross the zero $\mathrm{GtCO}_{2} / \mathrm{yr}$ threshold during the 2050-2065 timeframe, consistent with the emissions trends implied by Article 4 of the Paris Agreement'. 


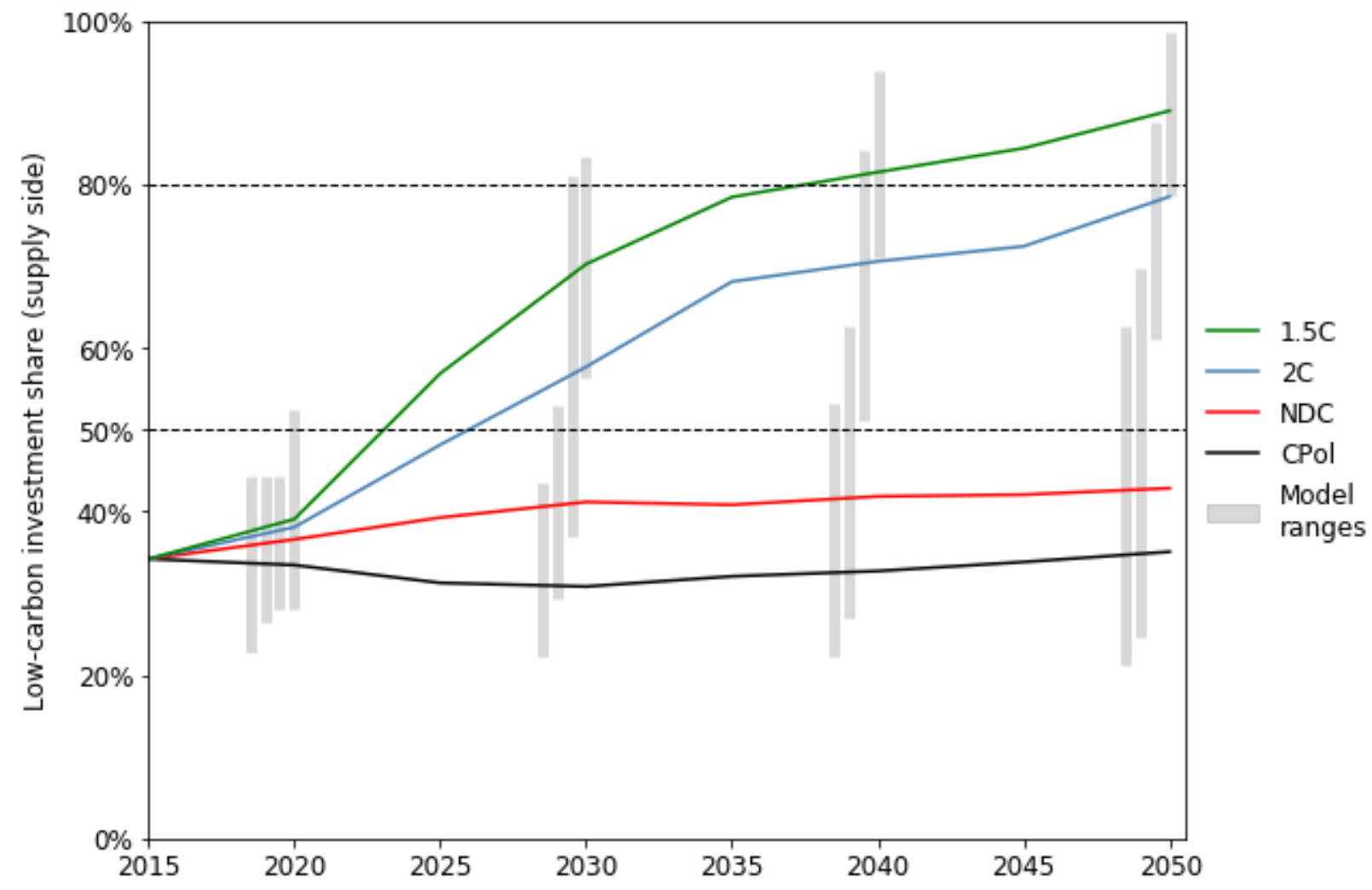

Figure 5. Projected global average annual low-carbon energy supply-side investments as a share of total supply-side investments. Solid lines represent multi-model means; floating bars give the min-max ranges across the models. Estimates shown here include supply-side investments in renewable electricity and hydrogen production, bioenergy extraction and conversion, uranium mining and nuclear power, fossil energy equipped with CCS, and the portion of electricity T\&D and storage investments that can be attributed to low-carbon electricity generation. Dashed lines denote important thresholds for low-carbon energy investment.

\section{Low-carbon energy investment gaps}

Another way to illustrate the up-scaling requirements for low-carbon energy and energy efficiency in the NDC-achieving future and transformational $2{ }^{\circ} \mathrm{C}$ and $1.5^{\circ} \mathrm{C}$ pathways is to assess their 'investment gaps' - i.e., the total incremental investment needs for these cleaner options beyond those likely to happen anyway based on a continuation of today's trends, assuming no future tightening of energy and climate policies worldwide, as is envisioned in the 'CPol' reference case. Gap metrics of this type offer an alternative to the commonly used 'emissions gap' concept ${ }^{33}$. Because investments represent a lever that policy makers and investors can use to affect emissions, quantifying such gaps is important. As presented in Supplementary Table 1, achieving the current NDC pledges of countries implies that a global near-term (to 2030) low-carbon energy and energy efficiency investment gap ('LCEI-Gap') of approximately 130 billion US\$/yr (model mean), accounting for around $7 \%$ of all energy investments worldwide in 2015 , needs to be filled over the next several years. If the aim is instead to keep global temperatures below $2{ }^{\circ} \mathrm{C}$ or $1.5^{\circ} \mathrm{C}$ in the long term, then this near-term LCEI-Gap quickly escalates to 300 or 460 billion US $\$$ /yr, respectively (or $17-26 \%$ of 2015 investments). Looking toward mid-century, the global LCEI-Gap reaches far higher 
levels in each scenario, with the relative up-scaling of investment effort being particularly strong in the $2{ }^{\circ} \mathrm{C}$ and $1.5^{\circ} \mathrm{C}$ futures.

From a regional and national perspective, the largest LCEI-Gaps are identified for the countries of Asia and those comprising the OECD (Organisation for Economic Co-operation and Development), specifically China, India, Europe, and USA. That said, it is noteworthy that the nearterm LCEI-Gaps for USA, Europe, and Latin America are only marginally greater in the '2C' pathway than in the 'NDC' case, indicating that the level of low-carbon energy and energy efficiency investment needed to fulfil the Nationally Determined Contributions of those countries would already put them on track for achieving the $2{ }^{\circ} \mathrm{C}$ target in the longer term. (That is not to say, however, that the portfolio of projects invested in would look the same in these two diverging futures.) The '1.5C' pathway, in contrast, demands a considerably stepped-up investment effort in all regions and countries: put differently, the level of low-carbon investment required for achieving the NDCs is insufficient for setting the world on course for achieving the $1.5^{\circ} \mathrm{C}$ target. This is even truer when looking beyond 2030 toward mid-century. Furthermore, we note that while the LCEIGap for some regions/countries may appear to be rather low in absolute dollar terms, it could actually be fairly large in relative terms, i.e., as a share of a particular economy's future investment needs in the 'CPol' baseline. India is a prime example.

\section{Energy sector investments and financing needs for other SDGs}

The '2C' and '1.5C' transformation pathways depicted by the models are in all cases consistent with two of the three targets underlying Sustainable Development Goal \#7 (SDG7, focused on energy), namely a substantial increase in the share of renewables (Target 7.2) and a doubling of the rate of energy efficiency improvement (7.3), both by $2030^{10}$. They are also in keeping with SDG13 (Climate action), which refers to the Paris Agreement's aim of limiting global temperature increase to 'well below 2 degrees' during the $21^{\text {st }}$ century. Thus, the energy investment needs presented above for the transformational pathways reflect the achievement of critical parts of SDG7 and SDG13.

Other questions worth posing include how does the scale of these energy investments relate to those for making progress on other SDG targets, and might the investment needs for these other SDGs be affected by the energy and climate policies required for achieving SDG7 and SDG13? Figure 6 summarizes our answers to these questions. Firstly, we see that the total capital needs consistent with an energy system that is fundamentally transformed (or at least on that path by 2030) are an order of magnitude larger than the needs quantified here for most other SDG targets: a couple trillion dollars vs. a few hundred billion (or less). Note that the values presented reflect, in most instances, total sectoral investments in a world where the various SDG targets are met, as opposed to incremental investments relative to today or to some reference case. (Food security is an exception in that it represents the policy costs to compensate the poor for any increases in food costs beyond the 'CPol' baseline.) Secondly, our calculations indicate that the financial requirements for achieving or making substantial progress on the SDG7 energy access and SDG2 food security targets would necessitate greater financial flows in a world where energy and climate policies are significantly tightened, whereas those needs would be roughly the same or lower (thus cost savings) 
in the case of the SDG3 air pollution and SDG6 clean water and sanitation targets. With respect to the former (SDG7 energy access and SDG2 food security), this is because the higher energy prices brought about by an energy system transformation (and the accompanying carbon pricing, whether explicit or implicit) would have feedbacks on other sectors of the economy; hence, policies (e.g., subsidies, fuel price support, food aid) would be needed to protect certain consumers from being worse off than otherwise. For air pollution (SDG3), this is because the replacement of fossil fuel combustion activities with clean and efficient alternatives (e.g., solar and wind power, electric vehicles) obviates the need for investing in expensive air pollution control technologies. Water infrastructure (SDG6) costs are found to be little affected by an energy system transformation, at least when focusing on the industry and households/municipal sectors, as we do. 


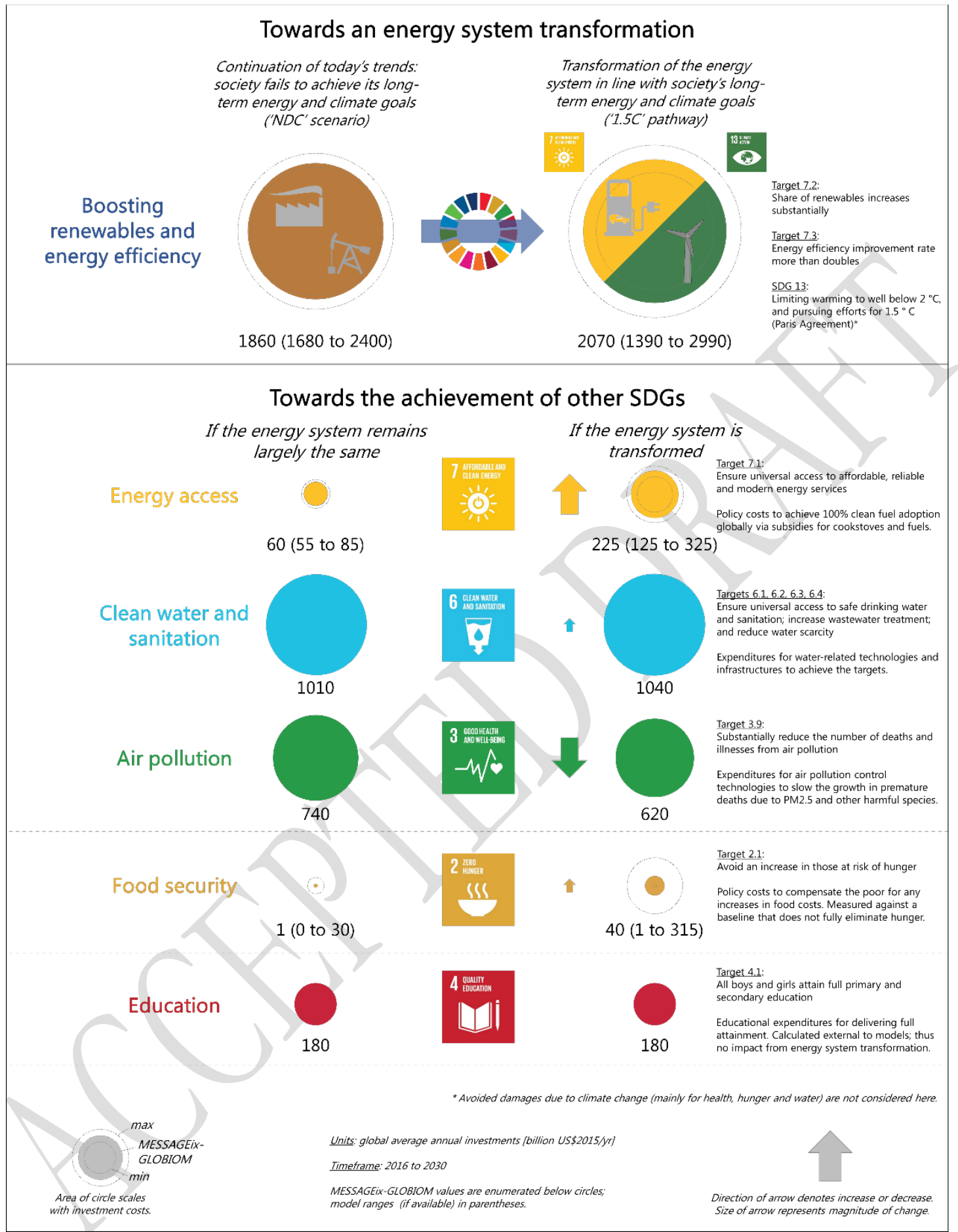

Figure 6. Projected investment needs to 2030 for achieving or making progress on a subset of SDG targets relevant for energy systems planning. Values in top section of diagram are derived directly from the global IAM energy investment results discussed previously. Values in bottom section ('other' SDGs) are calculated separately via diverse approaches. The starting point for analyses of the latter is that their targets must be achieved by 2030 , or significant progress must be made on them, whether the energy system is transformed (right side) or not (left side). We then assess the impacts that an energy transformation would have on these other SDG investment needs. Numerical values on left side (status-quo energy system) are from the 'NDC' scenario; values on right (transformed system) are from the ' $1.5 \mathrm{C}$ ' pathway. All investment values are undiscounted. SDG icons and colour wheel are the property of the United Nations. 


\section{Conclusions}

This paper summarises findings and insights from a systematic attempt to evaluate future energyrelated investment needs in multiple, plausible climate change mitigation scenarios, from a continuation of today's trends to achieving the $2{ }^{\circ} \mathrm{C}$ and $1.5^{\circ} \mathrm{C}$ targets, and to relate those investments to the financial requirements for making major progress on several other SDG targets. The entire exercise is carried out with a multi-model perspective, thereby lending a certain amount of robustness to the insights derived. Nevertheless, our analysis points to clear uncertainties in the energy investment landscape going forward. Importantly, underpinning all of the models' scenarios are population and socio-economic development assumptions in line with the 'middle-of-the-road' storyline of the Shared Socioeconomic Pathways (SSP2) The fact that there is little variance along this dimension is one potential caveat to our work; though, in practice we find that alternate assumptions do not have a major impact on the insights we derive, at least for one model. In other words, the multi-model means and ranges we report are not expected to differ a great deal in those alternative cases. The ranges would widen, to be sure, but not considerably, and one could expect SSP3 investment needs to be greater than those for SSP1 and SSP2 (see Supplementary Note 4).

From where exactly these investment dollars are summoned is outside the scope of our study, and for the most part beyond the capability of the models employed. To be sure, funding for individual projects could come from all manner of sources: businesses, governments, households, banks (private, state-owned, development), multilateral climate finance institutions, or via other means. And this funding could be sourced domestically or be provided by foreign entities. The ultimate funding portfolio, from the macro- to micro-scale, will be determined by some mixture of the world's financial system, countries' fiscal and monetary policies, and foreign development aid institutions, among others.

The good news, for backers of sustainable energy at least, is that the world's largest economies have already agreed that spurring low-carbon energy investments should be placed high on their collective priority list. One of the stated action items from the recent G20 Hamburg Climate and Energy Action Plan for Growth is "to create an enabling environment that is conducive to making public and private investments consistent with the goals of the Paris Agreement as well as with the national sustainable development priorities and economic growth" (see also Article 2.1c of the Paris Agreement ${ }^{9}$ ). In support of this effort, G20 countries have 'reemphasized' the previously agreed commitment of wealthy countries to jointly mobilise 100 billion \$/yr (during the period 2020-2025) for mitigation actions in developing countries. According to our analysis, this level of support would go a long way toward closing - if not fully covering - the low-carbon energy and energy efficiency investment gap faced by developing countries as they work to fulfil their NDC commitments. Considerably more capital would have to be mobilized, however, in order to close the investment gap for a $2{ }^{\circ} \mathrm{C}$ - or 1.5 ${ }^{\circ} \mathrm{C}$-consistent future. 
=ニニニニニニニニニニニニニニニニニニニニニニニ=

\section{METHODS}

=ニニニニニニニニニニニニニニニニニニニニニニニ

Overview of the policy scenarios run by the models

The following paragraphs provide additional information about the scenarios of this study on top of what is written in the main manuscript. For even more details, see the discussion in the Supplementary Methods as well as Supplementary Data 2 and Supplementary Data 3.

Current Policies (CPol)

Considers high-impact energy- and climate-related policies implemented in G20 countries as of 2015. These policies are included up to 2030; afterward, an assumption of equivalent effort, in terms of carbon emissions development, is assumed. Examples of policies include greenhouse gas (GHG) emissions reduction targets, GHG intensity reduction targets, and nuclear power and renewable energy targets.

Nationally Determined Contributions (NDC)

Assumes implementation of all countries' NDCs (conditional commitments) by 2030, the target year of most. Post-2030, an assumption of equivalent effort, in terms of carbon emissions development, is assumed (i.e., no intensification). The scenario thus represents a continuation of fragmented and highly diversified climate action worldwide.

Well Below 2 Degrees (2C)

Aims to hold the maximum increase in global average temperatures to $2.0^{\circ} \mathrm{C}$ (above the preindustrial level) over the course of the $21^{\text {st }}$ century with $>66 \%$ likelihood. Stylized, globally and sectorally comprehensive climate mitigation policies, in the form of carbon budgets, are included immediately after 2020 so as to limit carbon dioxide $\left(\mathrm{CO}_{2}\right)$ emissions from fossil fuel and industrial operations to approximately $1000 \mathrm{GtCO} 2$ over the 2011-2100 timeframe (actual model results vary). Emissions mitigation (after 2020) occurs where and when it is most cost-effective; no burdensharing regimes are in place. The pathway of the 'Current Policies' scenario is followed up through 2020.

Toward 1.5 Degrees (1.5C)

Aims to limit the increase in global average temperatures to $1.5^{\circ} \mathrm{C}$ (above the pre-industrial level) in 2100 with $>50 \%$ likelihood. Stylized, globally and sectorally comprehensive climate mitigation policies, in the form of carbon budgets, are included immediately after 2020 so as to limit $\mathrm{CO}_{2}$ emissions from fossil fuel and industrial operations to approximately $400 \mathrm{GtCO} 2$ over the 20112100 timeframe (actual model results vary). Emissions mitigation (after 2020) occurs where and when it is most cost-effective; no burden-sharing regimes are in place. The pathway of the 'Current Policies' scenario is followed up through 2020. 


\section{Technical documentation for the modelling frameworks}

Documentation for the six global energy-economy and integrated assessment models employed in this study (AIM/CGE ${ }^{11,12}$, IMAGE ${ }^{13}$, MESSAGEix-GLOBIOM ${ }^{14,15}$, POLES ${ }^{16,17}$, REMINDMAgPIE $^{18,19}$, and WITCH-GLOBIOM ${ }^{20,21}$, as well as for the nationally-focused GCAM-USA 22,23 model, can be found in the Supplementary Methods. For the global models, a particularly useful reference is The Common Integrated Assessment Model (CIAM) documentation website developed within the context of the ADVANCE project ${ }^{34}$. This site allows for side-by-side comparisons between different modelling frameworks.

\section{Overview of approaches for calculating SDG investment needs}

A diverse set of approaches has been used to calculate investment needs for achieving the other SDG targets by 2030. The following paragraphs summarise these while the Supplementary Methods section goes into further detail. Note that in some of these cases multi-model results calculated, while in other cases results from only the MESSAGEix-GLOBIOM model are available.

Renewable energy and energy efficiency (SDG Targets 7.2, 7.3)

Detailed energy sector investment results are reported by the full set of global IAMs.

\section{Energy access (SDG Target 7.1)}

Residential fuel price outputs are reported from the global IAMs for their South Asia and SubSaharan Africa regions. These prices are then delivered to the MESSAGE-Access fuel choice model as inputs. Investments are calculated as the policy costs for ensuring $100 \%$ clean fuel adoption throughout the world by 2030. The policies considered are subsidies for clean cookstoves and price support for modern fuels. Unique results for each of the global IAMs can be generated by MESSAGE-Access. See ref ${ }^{24}$.

\section{Clean water and sanitation (SDG Targets 6.1, 6.2, 6.3, 6.4)}

A specialized version of the MESSAGEix-GLOBIOM model is utilized for this analysis. The IAM is enhanced to include a reduced-form representation of the global water supply sector. The approach accounts for the rapid expansion of piped water access and treatment in the developing world, as well as the maintenance and replacement of existing water infrastructure in developed economies. Wastewater recycling and desalination technologies are also enabled as approaches to reduce freshwater withdrawals from rivers and underground aquifers. Water infrastructure investment needs, as well as additional energy and emissions resulting from the water sector development, are accounted for in the IAM explicitly. Results are only available from MESSAGEixGLOBIOM, not the other global IAMs. See refs ${ }^{27,28}$. 
Air pollution (SDG Target 3.9)

The GAINS model is used to estimate the number of deaths and illnesses results from air pollution under different air pollutant emissions pathways. The model also estimates the investments needed for air pollution control technologies that will limit air pollutant emissions to certain levels consistent with an extrapolation of current air quality legislation in cities/countries throughout the world. Projections for emissions and economic activities of different types - e.g., energy supply and demand, industrial production, transport, agriculture - are provided to GAINS from MESSAGEixGLOBIOM. Results are only available from MESSAGEix-GLOBIOM, not the other global IAMs. See ref $^{25}$.

Food security (SDG Target 2.1)

This target is interpreted for our purposes as avoiding any further increase in those at risk of hunger (over and above the baseline) due to energy and climate mitigation policies that promote a transformation of the global energy system. Unless appropriate safeguards are put in place, such policies can potentially have negative side-effects on food security by increasing agricultural prices as a result non- $\mathrm{CO}_{2}$ emissions abatement, greenhouse gas tax penalties on residual emissions, bioenergy expansion and afforestation. Therefore, in this work we define food policy packages that prevent such negative side-effects. In other words, the 'investments' we estimate for food security are actually the food policy expenditures needed to compensate the poor for any increases in food costs. These calculations are done externally to the IAMs. Carbon prices are taken from the IAMs, and then these are used to estimate the food policy expenditures (i.e., investments) required to limit those at risk of hunger. Unique results for each of the global IAMs can be generated by this methodology.

\section{Education (SDG Target 4.1)}

Attainment shares for those students finishing primary and secondary schooling by 2030 are obtained from educational projections developed externally to the IAMs. These shares are then multiplied by the number of people of school-age over this timeframe in the SSP2 scenario. Once the number of individuals in need of primary/secondary education has been calculated, a perstudent cost is applied to each, in order to estimate the educational expenditures over time and by country. Because these investments are calculated externally to the IAMs - and without any input from or feedback on them - the cost estimates do not vary in scenarios with either more or less energy system transformation. See ref ${ }^{26}$.

\section{Calculation of demand-side energy efficiency investments}

Demand-side energy efficiency investments across the end-use sectors (buildings, transport, industry) are calculated in a harmonized way for each of the models, utilising a methodology that was originally developed for the Global Energy Assessment ${ }^{3}$ and then adapted in the LIMITS project ${ }^{7}$. We further refine that methodology here. The methodology makes use of two separate energy efficiency components.

1. 'Base-year efficiency' component. This is calculated by taking the level of energy efficiency investments estimated globally by IEA in $2015^{30}$, which was 221 billion US $\$ 2015 / \mathrm{yr}$ (relative 
to a hypothetical counterfactual of a less-efficient world in that year), and then scaling those efficiency investments with total final energy demand in the models' scenarios (relative to 2015 final energy demand) to arrive at future estimates for those same values. Because the IEA only publishes a global number for the year-2015 efficiency investments, we only estimate a global value for the models in their future scenarios (i.e., no estimation of regional/national energy efficiency investments for this first component).

2. 'Supply-side offset' component. More specifically, we compared total final energy demand in each of the model's tightened policy scenarios ('NDC', '2C', '1.5C') to that model's demand in the reference case ('CPol'). We then made an assumption that, in equilibrium, the investments made to reduce energy demand could be equated to the investments that have been simultaneously offset on the supply side. This required, for a single model and region, calculating the ratio of supply-side investments in the policy scenario to total final energy demand in that same scenario and then multiplying this ratio (which is in units of $\$$ per exajoule) by the final energy demand reductions calculated separately for that policy scenario (relative to the reference case; units in exajoules). We then multiply that investment value (in $\$$ ) by the share of total GDP in the policy scenario to that in the reference case (in \%). These calculations are performed for each model time period and then cumulated over the timeframe of interest (e.g., 2016-2050).

The result is our approximation of a given country or region's investment into energy efficiency, taking into account any contraction in the size of its economy (hence economic contraction is not counted toward investment). It is an approximation in that it aims simply to give a sense of the scale of efficiency-related investments on the demand side. While it is not without its shortcomings, it does allow us to discuss supply-side investments alongside demand-side efficiency investments without completely ignoring the latter. Other demand-side investments could also be included to inflate the figures to larger values, for example by considering the component costs of appliances (more efficient cars, refrigerators, manufacturing equipment, and so on). This could lead to demandside investment estimates that are an order of magnitude higher. As discussed in ref ${ }^{35}$, estimates of demand-side investments are subject to considerable uncertainty, owing to a lack of reliable statistics and definitional issues (i.e., what exactly is a purely energy-related investment on the demand side?).

It is worth noting that our default methodology for calculating energy efficiency investments leads to estimates for the 2016-2050 timeframe that are roughly in line with those calculated by IEA ${ }^{6}$, even though the latter uses a somewhat more 'bottom-up' approach. More specifically, while in our '2C' pathway we calculate values of 640 billion US\$/yr (model mean; range of 480 to 890 billion US\$/yr), IEA puts the number at around 1120 billion US $\$ / y r$ in their analogous scenario according to their original calculations. Sensitivity analyses utilising an alternative methodology for calculating the models' efficiency investment estimates lead to values of 1270 billion US\$/yr (range: 960 to 1540 billion US\$/yr) in the same '2C' pathway (see Supplementary Note 5). Thus, our default methodology, while admittedly stylized, results in efficiency investments that are consistent with those utilising other, more bottom-up approaches. 
Carbon dioxide emissions reported in this paper include emissions from fossil fuels and industrial processes (FF\&I), but exclude land use. Cumulative emissions globally over the 2016-2100 timeframe range from 880 to $1074 \mathrm{GtCO}_{2}$ (mean: $952 \mathrm{GtCO}_{2}$ ) in the '2C' scenario and from 206 to $525 \mathrm{GtCO}_{2}$ (mean: $390 \mathrm{GtCO}_{2}$ ) in the ' $1.5 \mathrm{C}$ ' scenario. Cumulative $\mathrm{CO}_{2}$ emissions (FF\&I) over the historical period of 2011-2015 were roughly $165 \mathrm{GtCO}_{2}$. The cumulative emissions exhibited by the models are thus within the bounds of uncertainty for the 2011-2100 carbon budgets consistent with staying below $2{ }^{\circ} \mathrm{C}$ over the $21^{\text {st }}$ century with $>66 \%$ likelihood and with limiting temperature rise to $1.5^{\circ} \mathrm{C}$ in 2100 with $>50 \%$ likelihood ${ }^{4,36}$. And importantly, the cumulative emissions levels in the ' $1.5 \mathrm{C}$ ' case are markedly lower than other studies in the literature that have looked at long-term energy and climate mitigation investment needs in the context of the Paris Agreement.

\section{Currency conversion for model results}

The original investment results provided by the models focused upon this study were in units of 2010 US $\$$. Then, for the purposes of this paper, we converted those values to 2015US\$ by using a standardized GDP inflator of 1.087. This value comes from the World Bank Statistical Database ${ }^{37}$.

\section{Data availability}

All investment data supporting this analysis - including the numbers behind the tables and figures are available to any interested parties as online supplementary material to this paper (Supplementary Data 1). The CD-LINKS scenario database will also eventually house this information, along with a host of other data describing the various scenarios discussed here (e.g., energy and emissions timeseries by fuel, sector and region). The database will be available here when it is made public: https://db1.ene.iiasa.ac.at/CDLINKSDB/. 


\section{Acknowledgements}

The authors acknowledge funding provided by the World Bank and the European Union's Horizon 2020 research and innovation programme under grant agreement No 642147 ('CD-LINKS' project). SF is supported by the Environment Research and Technology Development Fund (2-1702) of the Environmental Restoration and Conservation Agency Japan and JSPS KAKENHI Grant Number JP16K18177. Peter Kolp of IIASA is also recognized for his assistance with Web database development and support. The views expressed by JD and AS are purely theirs and may not in any circumstances be regarded as stating an official position of the European Commission.

\section{Author Contributions}

$\mathrm{DM}, \mathrm{KR}, \mathrm{JR}, \mathrm{MF}$, and $\mathrm{CN}$ posed the initial research questions to frame the study and then selected the scenarios to analyse. VK, MG, OF, DH, SF, MH, DvV, HSdB, CB, EK, JE, LD, VB, JD, AS, and GI ran the integrated assessment models for obtaining the energy investments. VK, SiP, ShP, MPC, NR, PR, WS, and SF carried out the investment analyses for the other Sustainable Development Goals. WZ and DM compiled and analysed results from all models and analyses. DM and WZ led the writing of the manuscript, with all other authors contributing.

\section{Competing interests}

The authors declare no competing interests.

\section{Additional information}

Supplementary information is available for this paper at [to be decided].

Reprints and permissions information is available at www.nature.com/reprints.

Correspondence and requests for materials should be addressed to DM (mccollum@iiasa.ac.at).

Publisher's note: Springer Nature remains neutral with regard to jurisdictional claims in published maps and institutional affiliations. 


\section{$\underline{\text { References }}$}

Clarke, L. et al. Chapter 6 - Assessing transformation pathways, In Climate Change 2014: Mitigation of Climate Change. IPCC Working Group III Contribution to AR5. (2014).

2 Kriegler, E. et al. The role of technology for achieving climate policy objectives: overview of the EMF 27 study on global technology and climate policy strategies. Climatic Change 123, 353-367, doi:10.1007/s10584-013-0953-7 (2014).

3 Riahi, K. et al. in Global Energy Assessment - Toward a Sustainable Future 1203-1306 (2012).

4 Rogelj, J. et al. Energy system transformations for limiting end-of-century warming to below $1.5^{\circ} \mathrm{C}$. Nature Clim. Change 5, 519-527, doi:10.1038/nclimate2572 (2015).

5 Carraro, C., Favero, A. \& Massetti, E. "Investments and public finance in a green, low carbon, economy". Energy Economics 34, Supplement 1, S15-S28, doi:10.1016/j.eneco.2012.08.036 (2012).

6 OECD/IEA and IRENA. Perspectives for the energy transition - investment needs for a low-carbon energy system. (Organisation for Economic Co-operation and Development (OECD), International Energy Agency (IEA) \& International Renewable Energy Agency (IRENA), 2017).

7 McCollum, D. L. et al. Energy investments under climate policy: a comparison of global models. Climate Change Economics 04, 1340010, doi:10.1142/s2010007813400101 (2013).

8 G20. Annex to G20 Leaders Declaration - G20 Hamburg Climate and Energy Action Plan for Growth., (Group of 20 Countries, 2017).

$9 \quad$ UNFCCC. Paris Agreement, Decision 1/CP.17. (United Nations Framework Convention on Climate Change (UNFCCC), Paris, 2015).

10 UN. Transforming Our World: The 2030 Agenda for Sustainable Development (A/RES/70/1). (United Nations, 2015).

11 Fujimori, S., Hasegawa, T., Masui, T. \& Takahashi, K. Land use representation in a global CGE model for longterm simulation: CET vs. logit functions. Food security 6, 685-699 (2014).

12 Fujimori, S., Masui, T. \& Matsuoka, Y. AIM/CGE [basic] manual Discussion Paper Series. Center for Social and Environmental Systems Research, National Institute for Environmental Studies: Tsukuba, Japan (2012).

13 Stehfest, E. et al. Integrated Assessment of Global Environmental Change with IMAGE 3.0. Model description and policy applications. (PBL Netherlands Environmental Assessment Agency., The Hague, 2014).

14 Fricko, O. et al. The marker quantification of the Shared Socioeconomic Pathway 2: A middle-of-the-road scenario for the 21st century. Global Environmental Change 42, 251-267, doi:10.1016/j.gloenvcha.2016.06.004 (2017).

15 Krey, V. et al. MESSAGE-GLOBIOM 1.0 Documentation. (International Institute for Applied Systems Analysis (IIASA), Laxenburg, Austria, 2016).

16 Criqui, P., Mima, S., Menanteau, P. \& Kitous, A. Mitigation strategies and energy technology learning: an assessment with the POLES model. Technological Forecasting and Social Change 90, 119-136 (2015).

17 Keramidas, K., Kitous, A. G., Després, J. \& Schmitz, A. POLES-JRC model documentation. EUR 28728 EN. Report No. ISBN 978-92-79-71801-4, JRC107387, (Luxembourg, 2017).

18 Kriegler, E. et al. Fossil-fueled development (SSP5): an energy and resource intensive scenario for the 21 st century. Global Environmental Change 42, 297-315 (2017).

19 Luderer, G. et al. Economic mitigation challenges: how further delay closes the door for achieving climate targets. Environmental Research Letters 8, 034033 (2013).

20 Bosetti, V., Carraro, C., Galeotti, M., Massetti, E. \& Tavoni, M. WITCH: A World Induced Technical Change Hybrid model. Energy Journal 27, 13-37 (2006).

21 Emmerling, J. et al. The WITCH 2016 Model-Documentation and Implementation of the Shared Socioeconomic Pathways. (2016).

22 Iyer, G. et al. Measuring Progress from Nationally Determined Contributions to Mid-Century Strategies. Nature Climate Change (accepted).

23 PNNL. GCAM Documentation [http://igcri.github.io/gcam-doc/toc.html]. (Pacific Northwest National Laboratory, 2016).

24 Cameron, C. et al. Policy trade-offs between climate mitigation and clean cook-stove access in South Asia. Nature Energy 1, e15010 (2016).

25 Amann, M. et al. Cost-effective control of air quality and greenhouse gases in Europe: Modeling and policy applications. Environmental Modelling \& Software 26, 1489-1501 (2011). 
Abel, G. J., Barakat, B., KC, S. \& Lutz, W. Meeting the Sustainable Development Goals leads to lower world population growth. Proceedings of the National Academy of Sciences 113, 14294-14299, doi:10.1073/pnas.1611386113 (2016).

27 Parkinson, S. et al. Balancing energy impacts of global clean water targets. (IIASA Working Paper (WP-18-005). (International Institute for Applied Systems Analysis, Laxenburg, Austria, 2018).

Parkinson, S. C. et al. Climate and human development impacts on municipal water demand: A spatially-explicit global modeling framework. Environmental Modelling \& Software 85, 266-278 (2016). Riahi, K. et al. The Shared Socioeconomic Pathways and their energy, land use, and greenhouse gas emissions implications: An overview. Global Environmental Change 42, 153-168, doi:10.1016/j.gloenvcha.2016.05.009 (2017). OECD/IEA. World Energy Investment 2016. (Organisation for Economic Co-operation and Development (OECD), International Energy Agency (IEA), 2016).

31 OECD/IEA. World Energy Investment 2017. (Organisation for Economic Co-operation and Development (OECD), International Energy Agency (IEA), 2017).

32 Rogelj, J. et al. Paris Agreement climate proposals need a boost to keep warming well below $2^{\circ} \mathrm{C} . \mathrm{Nature} 534,631$ 639, doi:10.1038/nature18307 (2016). UNEP. The emissions gap report 2016. (United Nations Environment Programme (UNEP), Nairobi, 2016). ADVANCE contributors. ADV ANCE wiki: The Common Integrated Assessment Model (CLAM) documentation website [http:/ / themasites.pbl.nl/ models/advance/index.php/ADV ANCE wiki], 2017). Grubler, A. et al. in Global Energy Assessment - Toward a Sustainable Future 1665-1744 (2012).

Millar, R. J. et al. Emission budgets and pathways consistent with limiting warming to $1.5^{\circ} \mathrm{C} .10,741$, doi:10.1038/ngeo3031 (2017).

37 World Bank. World Bank Statistical Database [https:/ / data.worldbank.org/indicator/NY.GDP.DEFL.ZS.AD?locations=US], 2018).

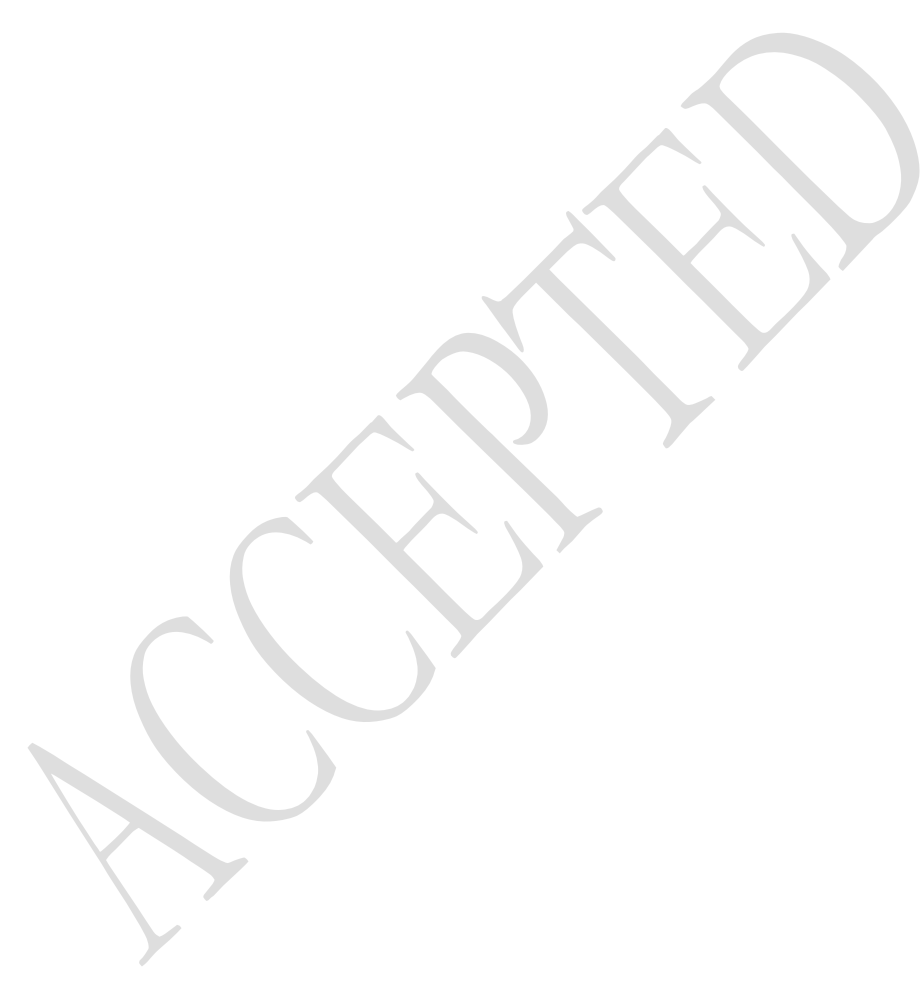

